\title{
Seismic Behavior of Two-Story Shear Wall with Concrete Filled Steel Tube Columns
}

\author{
Liwei Wu, Youpo Su, Jianwei Chen, Liutao Han
}

\begin{abstract}
To investigate the seismic behavior of concrete filled steel tube columns precast shear walls, a study of 3 specimens failure cases were conducted in Quasi-static loading. The shear walls were designed in $1 / 3$ scaled, and grouted sleeve connection detail were applied in steel tubular joints. The failure pattern, the hysteretic behavior, ductility and the energy dissipating capacity were discussed under different axial compression ratios. The results show: The failure mode is similar that steel tubular joints brittle failure occur. The hysteretic curve plumpness and energy dissipating capacities are strong. The ductility coefficient range from 1.6 2.5 and the deformation performance decreases with the increase of axial compression ratios. The yield strength in substituted for the ultimate strength in steel tubular joints design.
\end{abstract}

Keywords - Precast structure; Shear wall; Axial compression ratio; Seismic behavior

\section{INTRODUCTION}

Precast shear wall structure is a new building structure system that is suit for industrial production and on-site as sembly. Shear force and horizontal dis placement of layers are the main control factors in structure design. Therefore, horizontal seam, vertical seam and joint connection are relate to the reliability of structures directly.

Five shear wall specimens that shear span ratio is 2.25 were designed and tested in Tsinghua University ${ }^{[1]}$. Including one cast-in-place concrete wall, two full precast walls and two part precast walls were vertical cast-in-situ belt connected with commercial concrete and vertical reinforcement connected with grouting sleeve. Experimental shows that grouting sleeve connection transfer the vertical stress effectively. The failure pattern is reinforcement yields and concrete crush of the precast wall and it is similar with cast-in-place wall. The seis mic behavior of concrete filled steel tubular structures in different axial compression ratio and shear span ratio were analyzed ${ }^{[2]}$. Two cast-in-place specimens, seven precast concrete filled steel tubular specimens and two specimens with different forms of shear keys were tested. The result shows: the performance of "U"-shaped shear key that connects steel tubular concrete frame and shear wall is more strength. The seismic performance of

Liwei Wu, North China University of Science and Technology China, E-mail-ncst2014@126.com concrete filled steel tubular frame shear wall structure and cast-in-place are equivalent. A series of experiment are carried out on the connection of the pre-stressed grouting casing under the condition of large deformation and cyclic loading by Zhao, Grundy and Lee ${ }^{[3]}$. The ultimate load, energy consumption and friction coefficient were analyzed, and the calculate formula of energy consumption and effective friction coefficient were derived on the basis of accumulate slippage length grouting length and pre-stress value. Study shows that the thermal energy generated by the friction has positive function to the seismic performance of the joints. A experiment Study on the seismic performance of vertical connection between precast shear wall panels was designed by Arturo $^{[4]}$ to improve the transmis sion of horizontal load between the vertical beams, and the seismic performance of precast shear wall structure.

A large number of experiments show that the seismic performance of concrete filled steel tubular frame shear wall structure and cast-in-situ structure is equivalent ${ }^{[2,5-8]}$.

\section{OVERVIEW}

\section{A.Specimen design and production}

Three specimens of 2-storey precast concrete filled steel tubular columns shear walls were designed and tested. The specimens numbered with SW-1, SW-2, SW-3, and the axial compression were $0,0.2,0.1$. In order to regulate the failure pattern is flexural failure, the height-thickness ratio of specimens is greater than 8 and the height-width ratio is greater than 3, according to the JGJ3-2010 ${ }^{[9]}$. The actual size of shear wall was $1080 \mathrm{~mm} \times 1500 \mathrm{~mm} \times 160 \mathrm{~mm}$ (height and width and thickness) of each specimen. The geometry of specimen is shown in figure 1.

For the requirement of shear span ratio (greater than 3), a precast steel frame as the auxiliary loading implement was placed up to the specimen, and the height is $2290 \mathrm{~mm}$, as is indicated in figure2.

To ensure effective transmission of the shear load, two security measures, flange connection and short column connection, were adopted in the connection of the auxiliary loading steel frame and the specimen. Connecting flanges were arranged on the second floor on both sides of the steel tube. Steel short columns and reserved cylindrical tank on the top of specimen were connect with grouting material. The auxiliary loading steel frame design as is shown in figure 2.

The reinforcement of wall, floor and ground beam of 3 
specimens were same. Ground beam reinforcement adopt HRB400 rebar, and longitudinal reinforcement is arranged with $12 \square 25$, double row layout, stirrups arranged with C8@200, encryption on both sides of steel tube, as is shown in figure 3 . In order to ensure steel tube and base effective connection, rebar with $16 \mathrm{~mm}$ diameter were welded on the sleeve with $65 \mathrm{~mm}$ from both the up and down margin, and 4 200mm-length"I" steels were welded on the sleeve along the ring. The base concrete strength designed as C40. Walls reinforcement adopt HRB400,

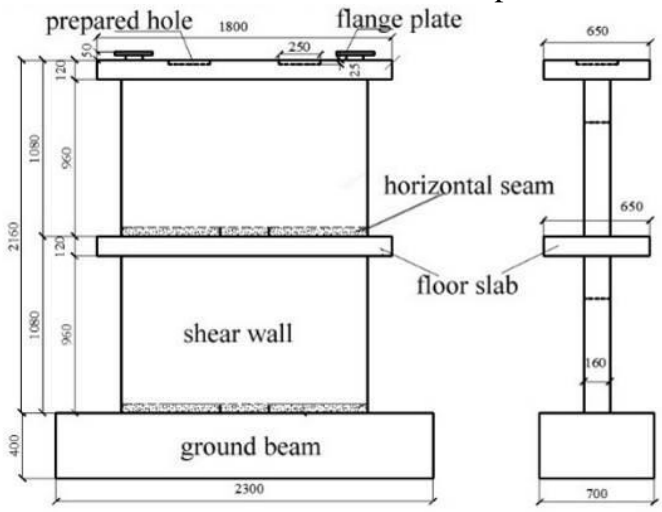

Fig. 1 The geometry of specimen

longitudinal reinforcement arrangement is arranged with $6 \square 10$, double row layout. Horizontal reinforcement arrangement is $6 \mathrm{C} 10$, double row layout, as is shown in figure 4 . The concrete designed as C30 self-compacting concrete, and the concrete filled in steel tubular is self-compacting concrete also, but the strength is C60. Each layer of the floor slabs reinforcement is $10 \mathrm{~mm}$ in diameter steel bars, arranged in double layer, and the concrete is C30 self-compacting concrete.

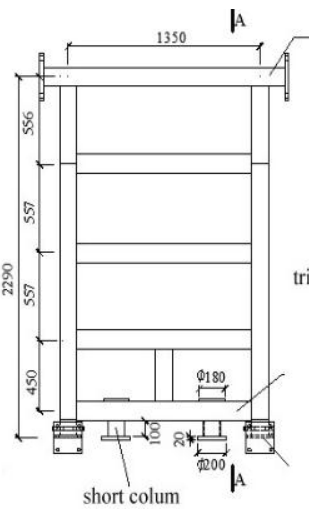

Fig.2 The auxiliary loading steel frame

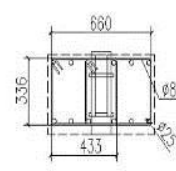

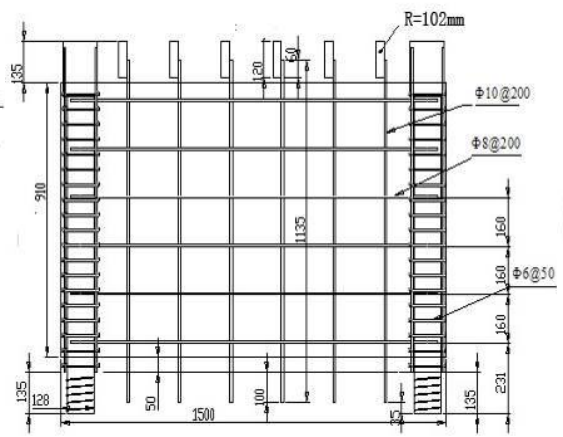

(a) the first floor

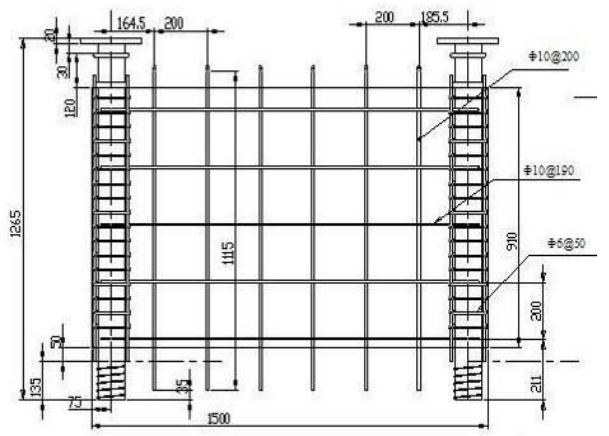

(b) the second floor
Fig.3 Detail reinforcement of ground beam

\section{B. Connect joints design}

The connect joints of the specimen consists steel tubular frame connect joints and vertical reinforcement connect joints. A new type of steel tubular sleeve grouting connect device in document ${ }^{[10]}$ was adopted. Conduct method is weld 5 circle spiral wire (diameter is $3 \mathrm{~mm}$ ) on the seamless steel tube which outer diameter is $102 \mathrm{~mm}$, flight lead is $25 \mathrm{~mm}$. Then, insert into the seamless steel sleeve which outer diameter of $133 \mathrm{~mm}$, depth of $135 \mathrm{~mm}$. The seamless steel sleeve weld 5 circle spiral wire (diameter is $3 \mathrm{~mm}$ ), and flight lead is $25 \mathrm{~mm}$ also. Finally, high-strength non shrinkage grouting materials is perfused in the annular gap.

Vertical reinforcement connection joint connect with the grouting connect device of the reinforcement bar sleeve in the document. The design method is steel sleeve which outside diameter and wall thickness is $32 \mathrm{~mm} \times 3.2 \mathrm{~mm}$ and the lower longitudinal reinforcement length of $60 \mathrm{~mm}$ are welded with sleeve. Then, insert the upper longitudinal steel bars into the steel casing, depth was $100 \mathrm{~mm}$. Finally, high-strength non
Fig.4 Detail reinforcement of walls shrinkage grouting material perfused in the annular gap.

\section{Material properties}

The concrete filled steel tubular composite frames consist of Q345 seamless round steel tubes with the outer diameter of $102 \mathrm{~mm}$, the thickness of $5 \mathrm{~mm}$, and self-compacting concrete of C60 was perfused to inside of the round steel tube. The sleeves of steel tubes were made of seamless round steel tube with the outer diameter of $133 \mathrm{~mm}$, the thickness of $4 \mathrm{~mm}$. The sleeves of reinforcements were made of seamless round steel tube with the outer diameter of $32 \mathrm{~mm}$, the thickness of $2.5 \mathrm{~mm}$. The mechanical properties of steel tubulars and reinforcements are shown in table 1.

Grouting materials was high strength and no shrinkage grouting materials, the measured standard test block compressive strength was $88.47 \mathrm{MPa}$, and the flexural strength was $9.61 \mathrm{MPa}$. The concrete of ground beam was commercial concrete, and the others were self-compacting concrete in the laboratory. The concrete block measured compressive strength were shown in table 2 . 
Table1 Mechanical properties of steel

\begin{tabular}{|l|l|l|l|l|l|}
\hline & $d / \mathrm{mm}$ & $f_{y} / \mathrm{MPa}$ & $f_{u} / \mathrm{MPa}$ & $\varepsilon_{y} / 10^{-6}$ & $E_{s}(\mathrm{MPa})$ \\
\hline \multirow{4}{*}{ steel tubular } & 102 & 384 & 534 & 1879 & $2.04 \times 10^{5}$ \\
\cline { 2 - 6 } & 133 & 327 & 453 & 1776 & $1.84 \times 10^{5}$ \\
\cline { 2 - 6 } & 32 & 428 & 624 & 1897 & $2.25 \times 10^{5}$ \\
\hline reinforcement & 10 & 413 & 591 & 2070 & $2.00 \times 10^{5}$ \\
\hline
\end{tabular}

Note: $d$ is diameter; $f_{y}$ is yield strength; $f_{u}$ is ultimate strength; $\varepsilon_{y}$ is yield strain; $E_{s}$ is modulus of elasticity.

Table2 Compressive strength of concrete

\begin{tabular}{|c|c|c|c|c|c|c|}
\hline \multirow{2}{*}{ parts } & ground beam & \multicolumn{3}{|c|}{ shear wall } & \multirow{2}{*}{ floor slab } & \multirow{2}{*}{ concrete filled steel tube } \\
\cline { 3 - 5 } & SW-1 & SW-2 & SW-3 & \\
\hline $\begin{array}{c}\text { compression strength } \\
\text { /MPa }\end{array}$ & 50.03 & 45.37 & 46.19 & 48.40 & 40.25 & 63.60 \\
\hline
\end{tabular}

\section{Loading device and system}

Loading control system was MTS hydraulic servo actuator (244.41S). The center line of actuator and the specimen is in the same vertical plane. The loading device consist of a horizontal loading device, an auxiliary loading implement, a fixing device and a vertical axial pressure device. The test loading device was shown in Figure 5.

Loading system was Quasi-static test method in low cyclic loading. Before loading, the vertical axis force was applied by hydraulic jack, and the axial pressure was kept constant. In order to remove the influence of instrument and equipment, preloading with horizontal displacement of $3 \mathrm{~mm}$ is carried out, and formal loading begins after 2 cycles. Loading process was controlled by displacement, loading rate was $0.1 \mathrm{~mm} / \mathrm{s}$. Loading control system was divided into two stages: before and after the steel tubulars on both sides yield. At the first stage, the purpose was to find the yield displacement of the steel tubular, which was to be applied to the second stage. After the steel tubular yield, the control quantity was the yield displacement, which was the integer times of the yield displacement. The second stage loading cycle 2 cycles in each grade. The test loading system was shown in figure 6.

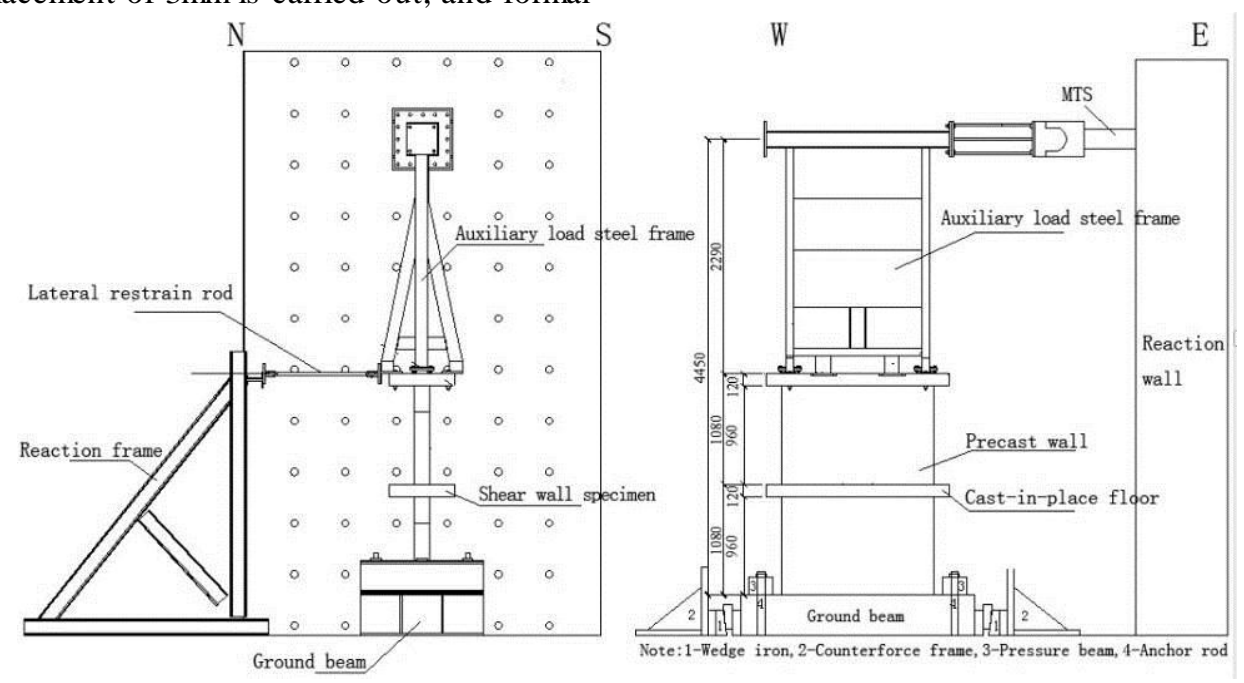

Fig.5 The loading device figure

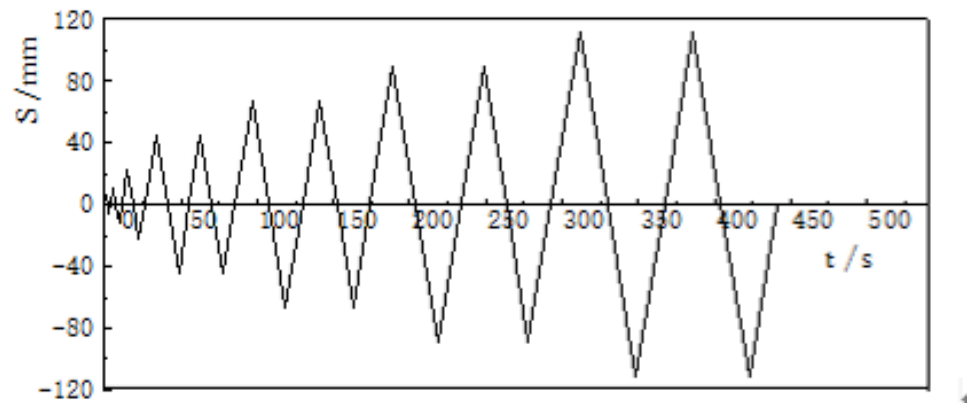




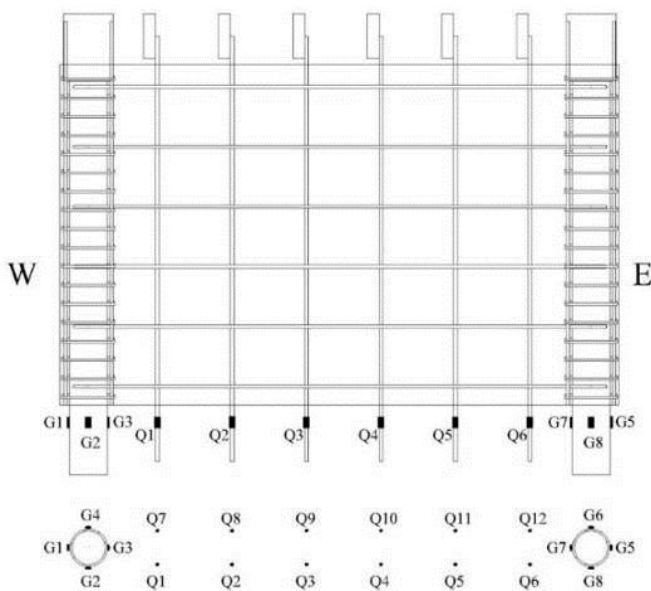

Fig.7 Layout of strain gauge measuring points
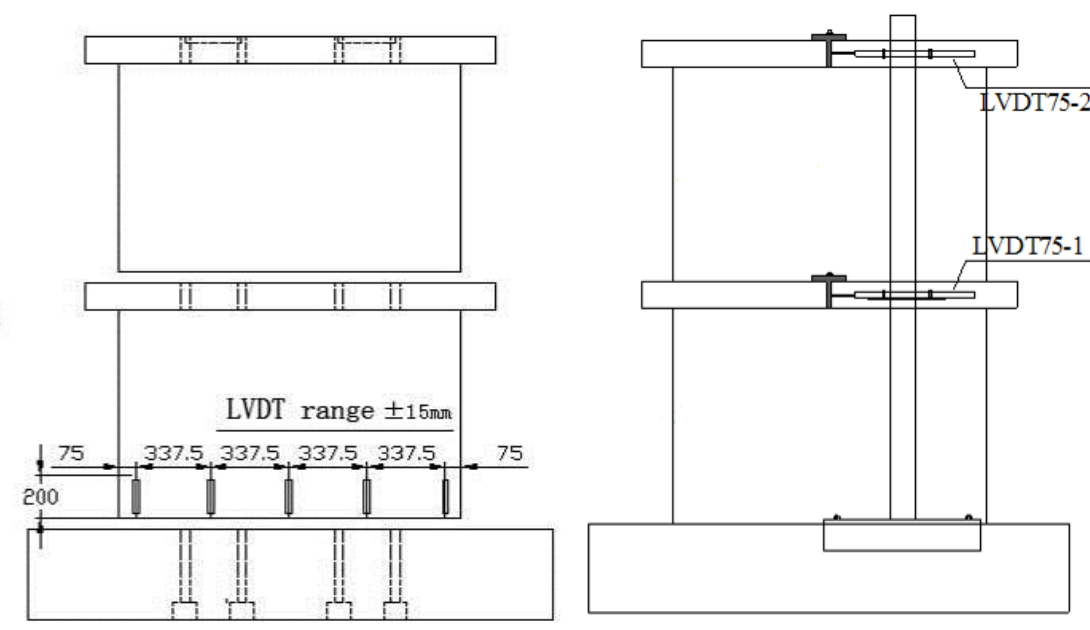

Fig.8 The instrument layout plan

\section{E. Layout of measuring points and measurement}

Experimental data include reinforcement and steel tube strain, the strain at the bottom section of wall, horizontal dis placement of the top of the wall and the slippage of the horizontal s eam. The strain of the reinforcement and the steel tube are measured by the strain gauge that is pasted on the wall of longitudinal reinforcement locating at the bottom of the position of $125 \mathrm{~mm}$ and steel tube located at the end of the position of $175 \mathrm{~mm}$. As is indicated in figure 7. The strain at the bottom section of wall is measured by 5 LVDT displacement sensors with $\pm 15 \mathrm{~mm}$ range and are arranged uniformly, as is shown in figure 8. Horizontal displacement of the top of the wall is measured by LVDT displacement sensor with $\pm 75 \mathrm{~mm}$ range fixed on the base.

\section{RESULTS AND ANALYSIS}

\section{A. Failure pattern}

The crack formation and development of each specimen were similar, and the failure pattern of the specimen was subject to bending shear failure. When the angular displacement was large enough, the node brittle destroy occurs. The damage process divided into 4 stages.

1) Elastic stage

At this stage, the loading displacement was small, and the bearing capacity rises linearly with the increase of loading displacement. There was no obvious residual strength and residual displacement.

2) Cracking stage

The cracking angular displacement of each specimen are $1 / 840,1 / 717$ and 1/717 respectively, and the cracking load are $95.64 \mathrm{kN}, 145.98 \mathrm{kN}, 184.18 \mathrm{kN}$ respectively. The crack of WA-1 appears in lower position on the west side of first layer, the SW-2 and SW-3 appear in upper position on the west side of first layer.
The characterize is small cracks, and extend to the wall of lower part rapidly.

2) Yield stage

The yield angular displacement of each specimen are 1/204 $1 / 203 、 1 / 203$ respectively, and the yield loads are $270.61 \mathrm{kN}$ 、 $360.15 \mathrm{kN} 、 320.23 \mathrm{kN}$ respectively. Multiple horizontal cracks appear on both sides of the first layer, and obliquely downward extension. With the increase of displacement and loading times, cracks extend and widen unceasingly.

3) Destroy stage

The ultimate load of SW-1, SW-2 and SW-3 are $276.57 \mathrm{kN}$ 、 $426.23 \mathrm{kN} 、 383.01 \mathrm{kN}$ respectively, and the ultimate angular displacement are $1 / 53 、 1 / 77,1 / 83$ respectively. In this stage, cracks extend and widen are the main phenomena, and eventually form a multiple cross " $\mathrm{X}$ "-shaped crack. When destroyed of the SW-1, steel tubular which located in the east was broke away fromground beam, as is shown in figure 9(a). For SW-2 and SW-3 steel tubular which located in the west was broke away suddenly from the floor, as is shown in figure 9(b).

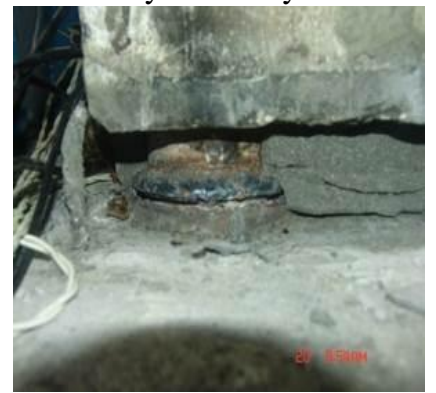

(a)

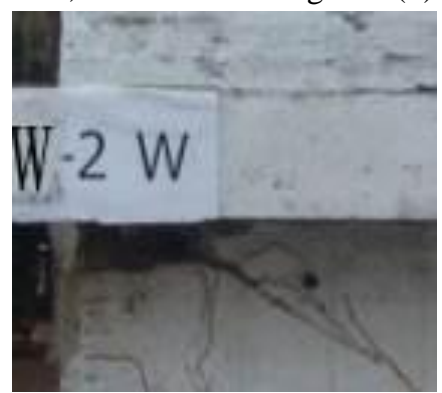

(b)
Fig.9 The local damage drawing 


\section{B. Hysteresis curves}

Hysteresis curves of the three specimens were indicated in Figure 10 where $F$ is the actual load value, and $\delta 2$ is the actual displacement value of the second floor. The figures shows: in early stage, the curves of three specimens are approximate linear relationship, and the hysteresis loop surrounding area is relatively small. The residual stress and the residual

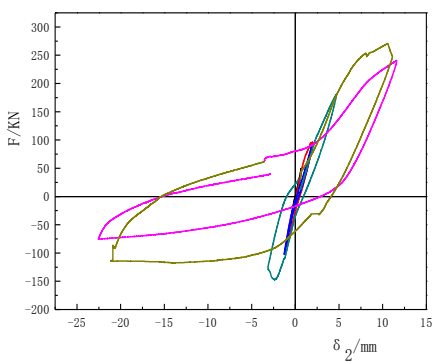

(1) SW-1

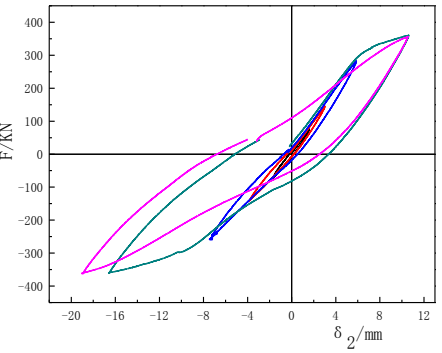

(2) SW-2
Fig. 10 The hysteresis curve

\section{Skeleton curve}

Skeleton curves of the three specimens are shown in Figure 12 where $\mathrm{F}$ is the actual load value, and $\delta 2$ is the actual displacement value of the second floor. The figure shows: before cracking, the growth tendency of skeleton curves is linear. Then before steel tube yields, with the increase of the control displacement, the skeleton curves incline to horizontal transverse axis, and convert from elastic to plastic. After the steel tube yield, the skeleton curves incline to horizontal transverse axis obviously, and the slope of skeleton curves reduce, but no falling section. With the increase of axial pressure, the ultimate load increase obviously, and the stiffness increase, the ductility reduce.

\section{Energy dissipation analysis}

The energy dissipation evaluate with equivalent viscous damping coefficient $(\xi)$, and the greater of the equivalent viscous damping coefficient, the higher of the capacity of energy dissipation. the results are shown in Table 3.

$$
\xi=\frac{1}{2 \pi} \cdot \frac{S_{2}}{S_{2}}
$$

Type:

$\xi$ is equivalent viscous damping coefficient

$S_{l}$ is the area of hysteresis loop

$S_{2}=S_{\triangle O B E}+S_{\triangle O D F}$

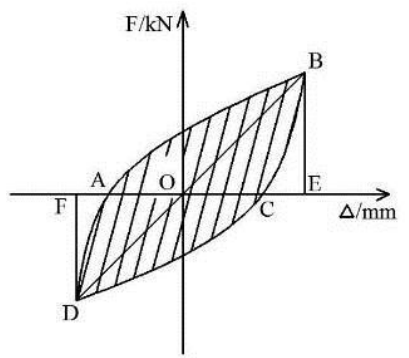

displacement are inconspicuousness, and the specimens are in the elastic stage. After the steel tubes on both sides of the wall yield, as the control dis placement increasing gradually, hysteretic curve slope gradually reduce. The hysteres is loop surrounding area increase, and the ability of energy dissipation improves. With the increase of axial compression ratio, ultimate load increase, but ductility reduce.

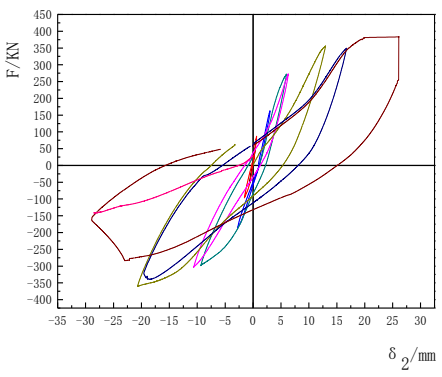

(3) SW-3

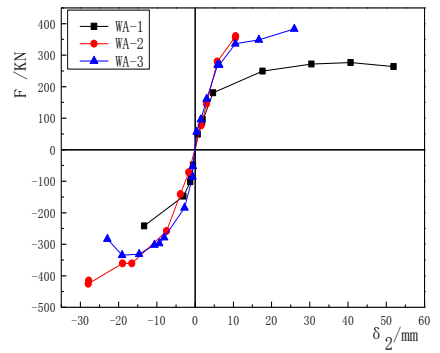

Fig.11 The skeleton curve
Fig.12 Calculation diagram

Comparing the energy dissipation values of 3 specimens, the values of SW-2 and SW-3 reduce by $10.2 \%$ and $7.7 \%$ compared to SW-1, and the equivalent viscous damping coefficient reduce by $6.7 \%$ and $5.7 \%$. So with the increase of axial compression ratio energy dissipation capacity reduce.

Table3 Comparison of energy dissipation

\begin{tabular}{ccccc}
\hline numbers & $\begin{array}{c}\text { energy } \\
\text { value } \\
\text { /kN.m }\end{array}$ & $\begin{array}{c}\text { increase } \\
\text { amplitude }\end{array}$ & $\begin{array}{c}\text { coefficient } \\
(\xi)\end{array}$ & $\begin{array}{c}\text { increase } \\
\text { amplitude }\end{array}$ \\
\hline SW-1 & 8.37 & 0 & 0.314 & 0 \\
SW-2 & 7.52 & $-10.2 \%$ & 0.239 & $-6.7 \%$ \\
SW-3 & 7.72 & $-7.7 \%$ & 0.296 & $-5.7 \%$ \\
\hline
\end{tabular}

\section{E. Stiffness degradation}

Figure 13 is the graph of stiffness degradation curve where $\mathrm{K}$ is the secant stiffness in each cycle, and $\delta_{2}$ is the actual displacement value of the second floor. The figure shows: The stiffness degradation regular of 3 specimens is basically same. Before cracking, the stiffness degrade rapidly, specimens in the elastic stage. After cracking, the stiffness degradation curves tend to gentle, then basically parallel to abscissa after ultimate loading. Observing the tendency of three curves, with the increase of axial compression ratio, the stiffness increase. 


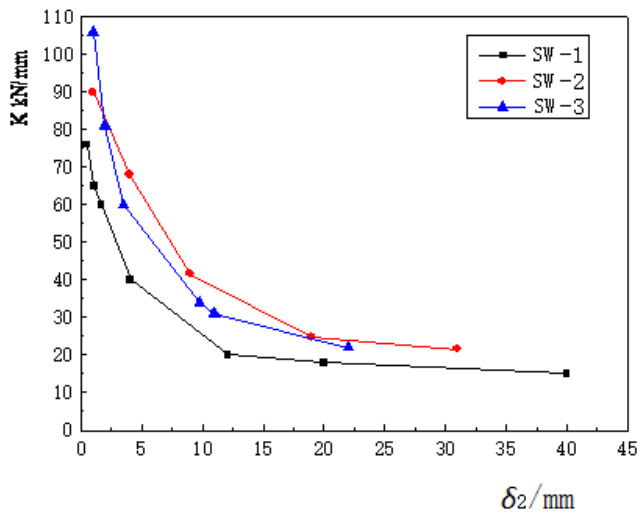

Fig.13 The stiffness degradation curves

\section{F. Ductility}

The ductility performance is evaluated by displacement ductility coefficient, the larger the displacement ductility coefficient, the better the ductility performance. Displacement ductility coefficient $(\mu)$ is calculated by formula $\mu=\Delta \mathrm{u} / \Delta \mathrm{y}$ where $\Delta \mathrm{u}$ is yield displacement, and $\Delta \mathrm{y}$ is ultimate displacement. Calculation results are shown in Table 4 where $\Delta y$ is yield displacement, and $\Delta \mu$ is ultimate displacement. The table shows that the ductility coefficient between 1.6 2.5 lower than the others. The main reason is that the material performance of steel tube is poor that no obvious yield level. After yield, the steel tube enter the intensive phase soon. The ductility coefficient of three specimens is $\mu 1>\mu 2>\mu 3$, which indicate that the ductility decrease with the increase of the axial compression ratio.

Table4 The ductility coefficient

\begin{tabular}{ccccccc}
\hline \multirow{2}{*}{ numbers } & \multicolumn{2}{c}{$\Delta_{y} / \mathrm{mm}$} & \multicolumn{2}{c}{$\Delta_{\mu} / \mathrm{mm}$} & & \multicolumn{1}{c}{$\mu$} \\
& positive & negative & positive & negative & 3.06 & 2.25 \\
SW-1 & 4.71 & 1.26 & 10.58 & 27.81 & 1.83 \\
SW-2 & 5.81 & 16.54 & 10.61 & 19.07 & 1.68 & 1.98 \\
SW-3 & 13.11 & 9.37 & 25.95 & 2.04 & negative \\
\hline
\end{tabular}

Note: Positive and negative are the directions of push and pull

\section{CONCLUSION}

1 ) The failure pattern of shear walls in different axial compression ratio is similar with joint brittle destroy. The main reason is that the material performance of steel tube is poor that no obvious yield level. After yield, steel tube enter the intensive phase soon. Therefore, the failure pattern is not perfect.

2 ) Precast concrete filled steel tubular columns shear wall structure is a promising structure with strength energy dis sipation capacity and better hysteretic behavior. The effect of axial compression ratio must be considered in structure design. With the increase of axial compression ratio, the deformation ability and ductility reduce, and the stiffness and energy dissipation capacity increase.

3 ) For the steel tube with no obvious yield level, the tensile strength should be used as the basis for the design.

\section{REFERENCES}

[1] QIAN Jiaru, PENG Yuanyuan, ZHANG Jingming, et al. Tests on seismic behavior of pre-cast shear walls with vertical reinforcements spliced by grout sleeves[J]. Building Structure, 2011, 41(2): 1-6.

[2] CAO Wanlin, WANG Min, WANG Shaohe, et al. Aseismic research of composite shear wall and core walls with rectangular concrete filled steel tube columns[J]. Engineering mechanics, 2008, 25(1): 58-70.

[3] Xiao-Ling Zhao, Paul Grundy, Yee-Teck Lee. Grout sleeve connections under large deformation cyclic loading[C]. Proceedings of the twelfth international offshore and polar engineering conference, Japan, 2002: 54-59.

[4] Arturo E Schultz, R A Magana, M K Tadros, eta 1. Seismic resistance of vertical joints in precast shear walls[C]. Federation international Proceedings of the 12th congress, 1994, (1):23-27.

[5] JIANGHongbin, CHEN Zaixian, ZHANG Jiaqi, et al. Quasi-static test of precast reinforced concrete shear wall structure[J]. Journal of Building Structures, 2011, 32(6): 34-40.
[6] Fumiya Esaki, Masayuki Ono. Effect of loading rate on mechanical behavior of SRC shear walls[J]. Steel and Composite Structures, 2001, 1(2):201-212

[7] WU Liwei, CHEN Jianwei, SU Youpo. Experimental study on the shear performance of vertical joints for concrete filled steel tube columns and wall[J]. Structural Engineers, 2014, 30(4):126-130.

[8] ZHU Zhangfeng, GUO Zhengxing. Seismic performance research on wall-slab joints of new precast concrete shear wall structure[J]. Journal of earthquake engineering and engineering vibration, 2011, 31(1):35-40.

[9] 《Technical specification for concrete structures of tall buildings》 ( JGJ3-2010)

10] Chen Haibin, Wu Liwei, Su Youpo. Experimental study on tensile behavior of steel-to-sleeve grouting connection[J]. World Earthquake Engineering, 2016, 32(2):18-23. 